\title{
Animismo e tentação no conto Umas formas, de Guimarães Rosa
}

\author{
Animism and temptation in the short story \\ Umas formas, by Guimarães Rosa
}

\section{Marcos Lampert Varnieri Regina da Costa da Silveira}

Centro Universitário Ritter dos Reis - UniRitter - Porto Alegre - Brasil

Resumo: No conto Umas formas, de Tutameia terceiras estórias (1967), a poética do animismo se desvela. Lápides com epitáfios no cemitério contíguo à igreja formam com a "nave" o cenário que é frequentado por um padre, um sacristão e um maçom, um fantasma e um monstro, todos envolvidos em episódios insólitos, de aparição, tentação e medo. É pela teoria da alma, antes mencionada pelo próprio autor João Guimarães Rosa, que se dá uma leitura possível dos enigmas propostos no conto rosiano de temática não apenas religiosa. O animismo integra-se neste ensaio como aparato teórico-conceitual literário, mas também como conceito antropológico e filosófico. Nesta investigação, serão mencionados o filósofo Agostinho de Hipona, com seus conceitos teológicos sobre a tentação; o estudioso das religiões Graham Harvey, proponente do "novo animismo", os antropólogos Philippe Descola, e Eduardo Viveiros de Castro, com o perspectivismo e o multinaturalismo, filósofo e pesquisadores que oferecem uma base interpretativa à altura dos enigmas rosianos.

Palavras-chave: Tutameia terceiras estórias. Umas formas. Animismo.

Abstract: In the tale Umas formas, from the book Tutameia terceiras estórias published in 1967, the poetics of animism is unveiled. Tombstones with epitaphs in the cemetery next to the church form the scene with a priest, a sexton and a freemason, a ghost and a monster, all involved in unusual episodes of apparition, temptation and fear. It is by the theory of the soul, mentioned before by the author himself João Guimarães Rosa, that a possible reading of the enigmas proposed in the Rosian tale of not only religious theme is given. Animism is considered in this paper as a theoreticalconceptual literary apparatus, but also as an anthropological and philosophical concept. In this investigation, the philosopher Augustine of Hippo is mentioned, with his theological concepts on temptation; the scholar of religions Graham Harvey, proponent of the "new animism"; the anthropologists Philippe Descola and Eduardo Viveiros de Castro, with perspectivism and multinaturalism, philosopher and researches who provide an interpretative basis that meet the rosian enigmas.

Key-words: Tutameia terceiras estórias. Umas formas. Animism. 


\section{Introdução}

E como é que às criaturas confere-se andarem soltas, assim, separadas umas das outras, como bolas ou caixas, com cada qual um mistério particular, por aí? A gente aceita Adão e seu infinito quociente de almas. Não o tremendo esperdiçar de forças que há em todo desastre.

(Guimarães Rosa, em Tutameia terceiras estórias)

A obra de João Guimarães Rosa cedo mereceu uma leitura mergulhada nas teorias do insólito ficcional. Sua produção literária perpassa do mythos ao logos, trata do hermetismo, da história das religiões, das sociedades secretas, como a maçonaria, a cabala e seu misticismo. Essa multiplicidade de temas encaminha-se para investigações que engendram enigma e labirinto e que, afinal, resultaram em produções pautadas pela subversão da lógica e da racionalidade. Nessa pretensa subversão, o autor intenta que o infinito e o inacreditável convertam-se na realidade do cosmo transformado no sertão. Eduardo Coutinho (2014, p. 109-110) cita na íntegra a resposta de Guimarães Rosa na célebre entrevista a Günter Lorenz, e enfatiza a crença rosiana na "ressurreição e no infinito", mas observa que não se trata de uma "apologia à irracionalidade", um abandono à racionalidade; antes disso, trata-se de uma crítica em relação "à tirania, à sua supremacia sobre as demais formas de apreensão do real".

O infinito, com o símbolo da lemniscata, é imagem que se desenha ao final do romance Grande Sertão: Veredas, e que pode ser visto em suas múltiplas possibilidades no livro Tutameia terceiras estórias. São essas mininarrativas sucintas e enigmáticas que exigem por isso mesmo uma intervenção interdisciplinar, e cedo deflagram ao leitor a sobreposição dos limites do realismo mágico latino-americano para ressignificar o homem na travessia do humano em seu caráter ilógico.

Na mesma entrevista a Lorenz, Rosa afirma que "A lógica é prudência convertida em ciência; por isso não serve para nada [...] o homem não é composto apenas de cérebro." (COUTINHO, 2014, p. 109) (grifos nossos). Prudencinhado, um guia-decego, protagonista do primeiro conto de Tutameia terceiras estórias, é nome que deriva da palavra prudência, mas essa identidade se expressa apenas ao final da narrativa, ainda que desde o início o guia suplique para o delegado: "segure a alma de Seu Tomé se for capaz!"; "Mas eu não cismo como foi que ele do barranco se derrubou e rendeu a alma." (ROSA, 1976, p. 13) ${ }^{1}$.

Aos enigmas engendrados no primeiro prefácio, Aletria e hermenêutica, tramam-se o cômico e o excelso: "a gente na rua, puxando cego, concerne que nem se avançar navegando - ao contrário de todos", (p. 13), declaração que aponta para o significado possível do título do conto, Antiperipleia, e que pode ser lido como a proposta de Guimarães Rosa de ir contra a corrente da lógica. $O$ cego Seu Tomé, por sua vez, é símbolo da vidência, indivíduo que ignora as aparências enganadoras do mundo e, graças a isso, tem o privilégio de conhecer sua realidade secreta, profunda, proibida ao comum dos mortais; o cego participa do divino, é o inspirado, o poeta, o taumaturgo, afinal, o vidente: "o de nenhum poder, mas que adivinha mais do que a gente", "Cego suplica de ver mais do que quem vê" (p. 14). O cego Tomé, no entanto, acredita na beleza das mulheres conhecidas por ele apenas pelas descrições do guia, o que leva este à subversão do provérbio popular: "O pior cego é o que quer ver" ( $p$. 15). Uma das causas possíveis do acidente em que o cego se envolveu refere-se ao fato de ele "tornar a enxergar! Delírios, de paixão, cobiçação, por querer, demais, avistar a mulher" (p. 15).

No conto Como ataca a sucuri, é a vez de Pajão, morador do brejão, marimbu medonho, arrenegar-se diante de seu hóspede Drepes, homem "das trenheiras malditas" (p. 32): "E não é que um repisa, e crê, é o que ouve contar, em vez do verdadeiro avistado?" (p. 32). Coxo em seu modo sinuoso de andar, Pajão assemelha-se à sucuri: "estragando muito espaço" (p. 31). Integrado à

\footnotetext{
1 Todas as citações pertencem à mesma edição de Tutameia terceiras estórias. Citaremos, a seguir, apenas o número correspondente às páginas.
} 
ciência da natureza, esse personagem remete à antropologia (VIVEIROS DE CASTRO, 2013), quando se observa a afinidade entre os humanos e os animais. Drepes, por sua vez, "O terrível homem cidadão" que matou a sucuri, representa o domínio da técnica, a ciência da cultura. Nesse caso, o narrador questiona a credibilidade conferida às narrativas orais, em detrimento da observação direta da realidade. Já o narrador em Fantasmas dos vivos, do livro Ave, Palavra, alude à "gente que tudo muito vê, transvê, não se deixando ilusionar pela grossa aparência do nosso mundo objetivado." Em Sagarana, o protagonista de A hora e vez de Augusto Matraga renasce espiritualmente após experiência em que quase morre, ascese que se assemelha à de Santo Antão Anacoreta. Infinitos parecem ser os exemplos, fruto da imaginação criadora, das vivências e erudição do autor mineiro de Cordisburgo, João Guimarães Rosa (1908 1967), encontrados em Fiç̧ão Completa, obra publicada em dois volumes pela editora Nova Aguilar (1994), e em Magma (1997), seu livro de poemas, publicado pela Nova Fronteira. Por ora, examinemos aqui um dos quarenta minicontos de Tutameia, em suas pouco mais de três páginas, que se oferece múltiplo a leitores de áreas distintas.

Às descrições ilógicas, fruto da imaginação criadora e dos mitos reencenados, somam-se personagens e formas indefinidas, com a aparição de monstros, de imagens que beiram os estados oníricos, com a personificação de coisas e de animais. Como uma das possibilidades de apreensão do mundo real, essas formas ilógicas ao leitor de Tutameia se oferecem como uma representação de "mundos possíveis", expressão metafísica criada por Leibniz, que tem sido utilizada pelos estudos literários para designar também os novos discursos do fantástico. Dentre esses novos discursos, o realismo animista estaria para a literatura africana subsaariana, como o realismo mágico e o maravilhoso para a literatura latino-americana. Todos esses discursos interagem hoje na constelação do animismo.
Graham Harvey (2013, p. 5), professor da Open University e estudioso das religiões, observa em The Handbook of Contemporary Animism que o animismo é a crença nos espíritos e um modo de relação com os seres extra-humanos. O animismo pode ser duplamente definido: o do antropólogo Edward Tylor e da psicanálise de Sigmund Freud, e o Novo Animismo, criado por Harvey. Há que citar também o Realismo Animista do sul-africano Harry Garuba. O brasileiro Eduardo Viveiros de Castro (2013), por sua vez, centra-se no multinaturalismo ao considerar a relação dos indivíduos, dos animais e dos espíritos como um modo de interação entre espécies. É do interesse da antropologia mais recente destacar, da concepção animista, o perspectivismo xamânico. O xamanismo, siberiano em sua origem, hoje vem sendo estudado no Brasil como xamanismo amazônico. É assim que Viveiros de Castro, no livro A inconstância da alma selvagem (2013), investiga o perspectivismo e cita como exemplo o conto rosiano Meu tio o lauaretê, de Estas Estórias, para evidenciar a diferença entre o modo como os seres humanos veem os animais e como estes veem não apenas os humanos, mas outras subjetividades que povoam 0 universo, como deuses, espíritos, mortos, plantas, objetos, artefatos.

A dicotomia corpo e alma, hoje investigada junto ao conceito de animismo na obra de Viveiros de Castro (2013) e nos estudos de Philippe Descola (2015), sugere um retorno à filosofia agostiniana. Para tratar do animismo, o francês Philippe Descola, discípulo de Lévi-Strauss, apresenta o quadro das teorias sócio-antropológicas. Assim, o objeto que

possui elementos de fisicalidade e interioridade análogos aos seus, e isso eu chamo de totemismo; ou que a interioridade e fisicalidade deste objeto são inteiramente distintas da sua, e isso eu chamo de analogismo; ou que este objeto possui uma interioridade similar e uma fisicalidade diferente, e isso eu chamo de animismo; ou que este objeto é desprovido de interioridade, mas possui um tipo similar de fisicalidade, e isso eu chamo de naturalismo. Estas fórmulas definem quatro tipos de ontologias, isto é, sistemas de distribuição de propriedades entre objetos existentes no mundo, que em retorno fornecem pontos chave para formas sociocósmicas de associação e concepção de 
pessoas e não-pessoas. (DESCOLA, 2015, p.12) (grifos nossos).

No conto rosiano, existe a interação do animal e do humano, em presença da porca preta, monstroobjeto querido e temido, que interage com o padre, uma espécie de xamã, em sua mediação entre dois mundos, o cotidiano e o anímico, este como o ilógico mundo extra-humano.

Na obra de Guimarães Rosa, de modo geral, o herói deseja ver, como Riobaldo, "os todos pastos demarcados", mas o enigma-labirinto entre o Deus e - Diabo, sagrado e profano para ele e para o leitor persiste. Na afirmação do crítico Ettore Finazzi-Agrò (2001, p.71), existe em Guimarães Rosa "a procura do Objeto absoluto, da Verdade última", ou ainda, "a própria busca, os passos em volta do Objeto desejado e perdido, do monstrum querido e temido, escondendo-se nas entranhas do pensamento humano, lá onde ele confina e se confunde com a 'persistência do animal'”.

No que diz respeito ao enigma da alma [anima], cedo o homem com ele se depara, e sobre esse assunto há estudos que remontam aos présocráticos, passando pela reflexão dos clássicos filósofos gregos, teólogos, psicólogos, sociólogos, psicanalistas, físicos e hoje pelos antropólogos. Em Guimarães Rosa, o tema da alma acha-se ligado intrinsecamente à imagem do infinito, razão por que a questão se tornou tão importante para a compreensão da sua produção literária. Assim, para ler suas mininarrativas, uma investigação literária com método interdisciplinar torna-se inevitável. Em Sobre a escova e a dúvida, último prefácio da obra e que precede o conjunto de contos a que pertence Umas formas, o leitor depara-se com perguntas desconcertantes, tais como:

Quantas mangas perfaz uma mangueira enquanto vive? isto, apenas. Mais, qualquer manga em si traz, em caroço, o maquinismo de outra, mangueira igualzinha, de obrigado tamanho e formato. Milhões, bis, triz, lá sei, haja números para o Infinito. (p. 145) (grifos nossos).

Ao final desse prefácio, o narrador silencia, cedendo espaço mais uma vez para o infinito, para a teoria da alma: "Deus está fazendo coisas fabulosas. Para onde nos atrai o azul? - calei-me. Estava-se na teoria da alma." (p. 165) (grifos do autor).

$\mathrm{Na}$ amplitude infinita e labiríntica dos caminhos, o homem depara-se com as formas indefinidas, com seres híbridos que subtraem a clareza definitiva e em que a lógica torna-se "ninharia", "quiriquiri", "quase nada", expressões que encontram correspondência e se somam aos demais termos que conferem o sentido de "nonada", sinônimo da palavra "tutameia", conforme Glossário (p. 166). É como princípio vital que a alma foi objeto de especulação para Santo Agostinho: a existência de uma alma viva, animada pelo verbo.

\section{Da indefinição de Umas formas}

No título do conto, anuncia-se a indefinição de "Umas formas". A partir daí, o campo semântico metafísico referente ao mundo onírico do animismo instaura-se com uma lista considerável de palavras que denotam ações, termos e expressões que ora nomeiam entes insólitos, ora servem para qualificar o nebuloso. Assim, seguindo a ordem que as palavras têm no conto, registra-se o vocabulário: mortos, absurdo, um fantasma, o monstro, mofoso e confuso, escuro, o fantasma, assombrando-se, vislumbrar, mirável, visões, lume, aspecto de criatura, espírito, um que-retrato, imagem feitiça, enlevo incaptável, extra-humano, fenômenos, simulacro, prévios traços, visagem, espectro, ignóbil animal vulto, ímpio fulano, sagrado, as potências-do-ar, sem figuras, sopitados, torporava, ente, estupor, sombração, fusca massa, sono, avejão, abstruso espaço, imaginação, aparição, visão, diáfano, deixado de toda matéria. Trata-se de um vocabulário recolhido do conto que, se não esgota todos sintagmas, há de exemplificar e nortear a seguir as reflexões sobre o caráter insólito e o animismo no texto rosiano.

O enredo se desdobra com a ação de três personagens: o padre, o sacristão e o maçom, mais um fantasma, o da mulher morta ainda moça, e um monstro, representado pela porca preta. No intuito de investigar qual o mistério que dessacralizava o altar, 
cuidavam de espreitar o "ímpio fulano", cujos desmando e ultraje destruíam as alfaias conspurcadas do altar. O lugar é a "nave" de uma igreja com adro ao lado ou em frente onde jazem o Comendador Urbano Affonso de Rojões Parente, o Monsenhor Euzébio da Matta $^{2}$, este "praeclarus vir inclytys praelatus" (prelado duas vezes famoso) e a que "...na mocidade... dorme...", Dídia Doralena Almada Salgoso. Entre as intenções ocultas no texto de Guimarães Rosa, sua erudição denota familiaridade com os mitos de procedências diversas, alento poético-linguístico no emprego dos arcaísmos, habilidade para observação e escuta, seja ao acompanhar os personagens do sertão, seja ao reconhecer antigos e famosos "prelados", a exemplo do poeta, do séc. XVII, Monsenhor Euzébio. Em ambos os casos, são conferidas no texto "microbiografias". Sobre essa e outras ocorrências em Tutameia, o que o crítico Paulo Rónai assevera mostra-se aqui de modo especial muito oportuno:

\begin{abstract}
A instantâneos mal-esboçados de estados de alma sucedem densas microbiografias; a patéticos atos de drama rápidas cenas divertidas; incidentes banais do dia-a-dia alternam com episódios lírico-fantásticos. Entre os muitos critérios possíveis de arrumação vislumbra-se-me um sugerido pelo que, por falta de melhor termo, denominaria de antonímia metafísica. Essa figura estilística, de mais a mais frequente nas obras do nosso autor, surge em palavras que não indicam manifestação do real e sim abstrações opostas a fenômenos percebíveis pelos sentidos. (p. 199-200).
\end{abstract}

A precisão do tempo é marcada pelo relógio em Umas formas: a partir das "Dez da noite e lua nova" (p.180), quando o padre se introduz na igreja para derrotar o demônio. O tempo da narrativa transcorre em três novilúnios, que é quando se dá o aparecimento da "visagem": "De meses, o absurdo frequentava a cidade. Um fantasma primeiro, depois, o monstro." (p. 180). Além do susto na comunidade, o aparecimento do fantasma deixava sequelas, é o caso da toalha do altar que amanhecera rasgada no segundo novilúnio (p. 181). O horário de aparição do fantasma seria à meia-noite, quando cães uivavam

\footnotetext{
2 Trata-se do poeta Monsenhor Euzébio da Matta, citado na
} obra do séc. XIX (COSTA E SILVA, 1844, p. 183-190). com o aparecimento do "ignóbil animal vulto". Vigiado pelo sacristão e pelo maçom, o padre não os percebe escondidos no coro: "o fantasma tinha sido de mulher." (p. 180), observaram os dois. Acometido pelas tentações do demônio, o padre "nervoso moço" luta contra o desejo da concupiscência. Ele cogitara "em espécie instintiva de tristeza" que a imagem da mulher morta ainda jovem pudesse ser "mirável, formosa", "enlevo incaptável", do que "Ele se resguardava casto sob o tiro das tentações." É o elemento extra-humano, uma vez que "Não a pudera o padre vislumbrar.” (p. 180). Trata-se da aparição da "alma" de Dídia Almada.

O diálogo entre a obra de Guimarães Rosa e os pré-socráticos, entre eles o proponente dos paradoxos, Zenão de Eléia, séc. V a.C., sugere a leitura de Anaxágoras, em presença do caos e do intelecto: o Nous, a inteligência, um dos princípios da alma, é ordenador do caos. Para Platão, a alma é tríplice, estando em paralelo a cabeça, o coração e o ventre, à diferença de Aristóteles, para quem a alma perece ao perecer o corpo. Para Plotino, séc. III d.C., a Alma do Mundo surge como o princípio responsável pelo devir ou mudança das coisas sensíveis e criadoras do tempo e do espaço. Neste sentido, a mística neoplatônica apresenta-se como possibilidade para uma "teoria da alma", conforme a expressão rosiana (p. 165).

\section{A alma e a filosofia teológica}

No texto filosófico Confissões (1973), Santo Agostinho (354-430 d.C) considera a existência da "alma viva", animada pelo "Verbo", passando pelas águas, pelos répteis, pelos pássaros e desse modo a teoria da alma explicaria o que hoje se considera como as funções cognitivas: o imaginar, o perceber e o julgar. Para Agostinho, a alma não busca deslumbramentos de milagres para se enraizar na fé, e "a produção de uma alma viva", alegoria da alma cristã (Gênesis, 1, 24), ocorre por intermédio dos mensageiros da palavra divina. Alegoricamente, as paixões da alma são representadas como "alimárias mansas" e "animais domésticos domados", se os 
fiéis e os mensageiros souberem refrear-se na violenta bestialidade da soberba, no prazer inerte da luxúria, da fama enganadora da ciência. Reparemos a aproximação da ciência da natureza com a ciência da cultura, a comparação entre fisicalidade, no caso, a dos animais, e interioridade, a das paixões da alma.

De fato, os elementos simbólicos que perpassam o conto rosiano referem-se à religiosidade, de modo específico ao catolicismo, com a presença do padre, do sacristão, dos objetos de culto, o candelabro das sete velas e o incenso, do sagrado. Não obstante, convivem lado a lado em Umas formas símbolos da Igreja católica com a ordem secreta da maçonaria, em presença do terceiro personagem, o maçon. O tempo de três novilúnios, ou seja, as três manifestações do fantasma no conto rosiano, lembra, com efeito, a "Tríplice tentação", de Santo Agostinho, em Confissões, em que a concupiscência da carne, dos olhos e da ambição do mundo representam a proibição ou o tabu: "Ordenaste-me que me abstivesse das relações luxuriosas." (AGOSTINHO, 1973, p. 215). As imagens de obscenidades que vêm da memória durante o sono arrastam o homem ao deleite, indo até a aparência do consentimento e da ação. Nesse sentido, os três personagens masculinos no conto de Rosa encontram-se possuídos pelo medo e pelo mal que a aparição produz. Movido pela tentação e desejo luxurioso que a imagem feminina propõe, a situação do padre assim se desvela, "surdo, só ele imaginando-a: outro lume, morosa, obstinada em seu aspecto de criatura. Desde que origem?" (p. 180-181), passagem que remete a Santo Agostinho: "A ilusão da imagem possui tanto poder na minha carne, que, enquanto durmo, falsos fantasmas me persuadem a ações a que, acordado, nem sequer as realidades me podem persuadir." (AGOSTINHO, 1973, p. 215). Quanto à pergunta que se insere em itálico no texto rosiano, dela advém a presença de um mistério na origem da criatura imaginada de aspecto enigmático. Uma imagem que institui a culpa e a consequente expiação, razão pela qual o espírito deve ser resguardado da tentação.

De fato, na comparação entre o personagem clérigo e a reflexão do clássico sacerdote, filósofo e teólogo da Igreja Católica, desnuda-se a tentação da carne:

Onde está nesse momento a razão que resiste a tais sugestões quando estou acordado e permanece inabalável, quando as próprias realidades se lhe introduzem. Fechase, quando cerro os olhos? Dorme simultaneamente com os sentidos corporais? $E$ por que é que muitas vezes, mesmo no sono, resistimos, lembrados do nosso propósito, e nele permanecemos casto, não dando nenhum consentimento a tais enganos? Contudo, a diferença é tão grande, que, quando no sono nos sucede não resistir, ao acordar voltamos ao descanso da consciência. Por essa diferença é que vemos que não praticamos voluntariamente essas ações, dado o fato de sentirmos pena que tais atos se tivessem passado em nós. (AGOSTINHO,1973, p. 215-216).

O padre atravessava o mundo - calcadas as cabeças de Leviatã." (p. 181), ideias que remetem mais uma vez ao trecho do prefácio "Sobre a escova e a dúvida", que diz: "O mal está apenas guardando lugar para o bem. 0 mundo supura é só a olhos impuros." (grifos nossos). Quanto à presença de Leviatã, trata-se do símbolo do "monstro do caos primitivo" - e o caos lembra que Nous, a inteligência e o conhecimento, originou a ordem do cosmos na teoria do pré-socrático Anaxágoras (séc. 4 a.C.) - e o monstro primitivo é o que "a imaginação popular sempre temia que acordasse, atraído por uma maldição eficaz contra a ordem vigente" (CHEVALIER, 1995, p. 547). Na tentação, o padre "surdo só ele imaginando-a" (p. 180); "Moça - mulher - já na mente se lhe apresentara, enlevo incaptável, nem consolação; antes, de distraído alvitre: Doralena... Dídia... - relido lido em lápide." (p. 181), passagem que lembra o sagrado sendo violado pelo profano, ordem do mundo religioso atormentada pela desordem do abismo do caos. Para Santo Agostinho, no capítulo 16, intitulado Onde reside o mal, do livro A caminho de Deus, o mal é uma ausência de conhecimento do bem, o abismo. Ele assevera que procurou o que era a maldade e não encontrou uma 
substância, mas uma perversão da vontade desviada da substância suprema: "e tendendo para as coisas baixas: vontade que derrama as suas entranhas e se levanta com intumescência." (AGOSTINHO, 1973, p. 142).

Ao sentir o mundo em seu desvão ou em vão de descomedir-se, a situação do protagonista em Umas formas, ainda que no dever mais "canônico e teologicamente", soma-se ao estranhamento do maçom e do sacristão, perplexos e confusos diante da imagem feitiça, enlevo incaptável, extra-humano. Assim, o enigma se apresenta tanto na pergunta que concerne à reflexão do padre, quanto nas exclamações de pavor dos "créus", "tramados para ver" do esconderijo a possível "visagem": - "Nem há! e tem de acabar!", nas palavras do maçom; e "Cruz'-que! -" (p. 181), na exclamação abreviada do sacristão. Na frase do maçom, lê-se a necessidade de anulação do simulacro, do duplamente falso, entendido platonicamente como cópia da imagem que participa da Ideia eterna, a que não perece nem acaba. A inserção do maçom no templo cristão ocorre no conto de modo conciliador, observado na expressão "maçom paroquiano". Já para o sacristão, o narrador reserva o epíteto "sandeu", apontando para a diferença entre uma sociedade secreta e uma religião.

Se pensarmos na anima, a análise até aqui empreendida demonstra que as tentações que visam atingir a alma (psique) ou o espírito (pneuma), como querem os estoicos, não se isentam do corpo, pelo contrário, as tentações insurgem no indivíduo precisamente pela fisicalidade, e no conto rosiano: "O padre tapava-se o espírito, de mais." (p. 181). É quando os sentidos se entrelaçam em sensações do corpo e da alma, anulando a dicotomia do sagrado e do profano: a "ardida esperança", "o sagrado botavase enorme" (p. 182). Em continuidade, o texto alude ao silêncio sinestésico, presença na ausência: "sussurro nenhum ou tosse, partindo de recantos, aos cheiros de cera e insenso", prenúncio dos rituais sagrados, canônicos e compulsórios: "Ateou no altar o padre as sete velas, viera por ato imperado" ( $p$. 181-182) (grifos nossos). Nesse ritual bíblico
(ÊXODO, 25, 10-22), observa-se a simbologia do candelabro de sete velas como elemento ornamental da igreja, objeto comum entre a religião do sacristão e o ofício do maçom (um candelabro de Sete Braços está presente também na decoração de uma Loja Maçônica). Na multiplicidade de temas encontrada, o leitor torna-se, como antecipou Paulo Rónai, "Estonteado pela multiplicidade dos temas, a polifonia dos tons, o formigar de caracteres, o fervilhar de motivos", levando o leitor "a patéticos atos de drama rápidas cenas divertidas" (RÓNAI, In: ROSA, p. 199, 1976). Assim, à expressão "o sagrado botava-se enorme", o narrador de Umas formas acrescenta: "Teso, salmeou - contra os poderes do abismo, subidores: potências-do-ar, o maligno e o medonho" (p. 182). Para dar conta do caráter eclesiástico, o texto evoca passagens bíblicas, nas quais as formas aéreas conspiram com as tentações da carne:

Em que noutro tempo andastes segundo o curso deste mundo, segundo o príncipe das potestades do ar, do espírito que agora opera nos filhos da desobediência; Entre os quais todos nós também antes andávamos nos desejos da nossa carne, fazendo a vontade da carne e dos pensamentos; e éramos por natureza filhos da ira, como os outros também. (EFÉSIOS 2, 2-3).

O fantasma "tinha sido de mulher", "aparecera em toda parte", "os tardos passantes assobrandose", mas o padre, que a não pudera "vislumbrar", indagava-se: "Temem-na, mais, por mirável, formosa? - cogitara, em espécie instintiva de tristeza" (p. 180) (grifos nossos). A cena que atinge o auge da narrativa não se isenta da simbologia da cruz cristã e do olho que tudo vê entre os maçons: o padre, de joelhos, "braços em cruz", sobre a campa dos mortos, "o sacristão também se prosternou, junto ao harmônio. Recuara o maçom, até à parede, ao grande olho gradeado", referência à simbologia do olho que tudo vê, na tradição maçônica. "Sendo meia-noite. Sopitados, os três. Tanto o padre torporava?" (p. 182). Nesse ponto da narrativa, percebe-se a instauração da magia e do animismo que do padre, caído, gerara-se: "quadrúpede, formidando, um ente", e "em esgazeio de estupor" o 
maçom e o sacristão "viam o que tresviam. Sombração. A porca preta! Desdominada, massiva, peluda. (...) A porca porém saltara janela, avejão, no abstruso espaço - declarou o maçom. Ou tornou baixar, rente ao padre entranhando-se - só disse o sacristão - no cavo chão da tara e da larva." (p. 182) (grifos nossos). O animal sobrenatural, a porca manifestada, tal como surgiu, desfez-se. Voltou para as profundezas, pois, como bem indica o termo "larva", esta era um fantasma. O vocábulo larva em latim significava máscara, espectro, fantasma ou alma do diabo que se apodera das pessoas. Reentrou na terra, portanto, a criatura, aludindo ainda a tara sexual e aos vermes larvais. De volta a Santo Agostinho, agora no livro A Cidade de Deus (2012) ele observa a opinião dos platônicos, segundo a qual as almas dos mortos seriam demônios: "os homens, se foram virtuosos, transformam-se em Lares; maus, tornam-se Lêmures ou Larvas; quando não se sabe se foram bons ou maus, recebem o nome de deuses Manes." (AGOSTINHO, 2012, p. 406). Na leitura de Metafísicas Canibais (2013), do antropólogo Viveiros de Castro, retoma-se o termo larvatus prodeo, expressão que pode ser traduzida por "caminho mascarado", explicando-o como sendo a velha alma que retorna nos debates atuais, chamada, agora, de cultura, mente ou simbólico. Alude o autor ao debate dualista da relação alma e corpo, apropriado, no caso da narrativa rosiana, ao conflito vivido pelo padre diante de suas tentações: primeiro, espectral; depois, corporal na forma da porca negra. A manifestação da criatura farrusca seria uma metamorfose da alma inquieta de Dídia Doralena, uma máscara vestida para a assunção da forma carnal. Não há no texto informações sobre quais teriam sido os pecados da mulher que ao lado ou em frente à igreja jaz, então condenada a vagar no entre mundos. Da tríplice tentação, vai-se do excelso ao cômico: "Madrugada, o povo invadia a matriz de Nossa-Senhora-do-Parto, dando com os três, que patetas corriam lá dentro, beira paredes, em direções diversas, num incessar. Só a custo assoporaram-se." (p. 183). Seja como for, a tentação corporificada por um ser extra-humano ou por umas formas animistas serviu ao jovem padre para que atingisse um estado de graça. Ao fim do conto, ele está "afinado, novo, diáfano, reclaro, aí se sorrindo - parecia deixado de toda a matéria." (p. 183). Assim, não havendo explicação racional para o "estranhifício", "os detentores do ocorrido, maçom e sacristão, duvidavam, como ainda hoje, cada vez, daquilo, de que sempre um pouco mais se esquecem: imaginação, aparição, visão.” (p. 183). Com esse exemplo, a proposta da ilogicidade rosiana, declarada em sua entrevista a Günter Lorenz, mais uma vez se efetiva em sua narrativa ficcional.

Como se observou, o próprio Guimarães Rosa propôs, à sua maneira, a necessidade de se revisar a teoria da alma. Como por um espelho, os présocráticos, o platonismo e o neoplatonismo, e acentuadamente Santo Agostinho permitem hoje a retrospectiva sobre os tratados anímicos. De certo modo, percebe-se uma mostragem no conto Umas formas do que, da poética do animismo, se desvela na produção literária do autor como um todo - de Sagarana à Tutameia terceiras estórias, bem como nos livros publicados postumamente, passando pela obra máxima, o seu único romance Grande Sertão: Veredas. Como singularidade teórica que avança neste século, os novos discursos do fantástico, entre eles o novo animismo, apresentam-se aos antropólogos como possibilidades e modelos do perspectivismo e do multinaturalismo. Nessa direção, citações rosianas não têm sido poupadas pelos cientistas de outras áreas do conhecimento, justo porque a obra se oferece a diferentes leitores como mundos possíveis para investigar a condição humana em sua dicotomia, fisicalidade e interioridade, com o tema mais instigador e misterioso até hoje proposto: a alma humana, o infinito.

\section{Referências}

AGOSTINHO. A cidade de Deus: contra os pagãos parte I. Petrópolis: Vozes. 2012.

AGOSTINHO. Confissões. São Paulo: Abril Cultural, 1973. 
BÍBLIA. Bíblia de Jerusalém: Nova edição revista e ampliada. São Paulo: Paulus, 2013.

CHEVALIER, J.; GHEERBRANT, Alain. Dicionário de símbolos. Mitos, sonhos, costumes, gestos, formas, figuras, cores, números. 9a․ ed. Rio de Janeiro: José Olympio, 1995.

COSTA E SILVA, J.M. da. Epistola II. Ao Sr. José de Sousa Bandeira. In: Poesias. Lisboa: Tipografia de Antonio José di Rocha - Aos Martyres, no 13, 1844. p. 183 e 190). Disponível: https://play.google.com/books/reader Acesso: 06/12/2016.

COUTINHO, Eduardo F. Rompendo barreiras: ensaios de literatura brasileira e hispanoamericana. Rio de Janeiro: 7 Letras, 2014.

DESCOLA, Philippe. Além de natureza e cultura. Tessituras. Pelotas, v. 3, n. 1, p. 7-33, jan./jun. 2015.

FINAZZI-AGRO, Ettore. Um lugar do tamanho do mundo. Tempos e espaços da ficção em João Guimarães Rosa. Minas Gerais: Editora da UFMG, 2001.
HARVEY, G. (Org.). The handbook of contemporary animism. London: Routledge, 2015.

LORENZ, Günter. Diálogo com Guimarães Rosa. In: COUTINHO, Eduardo F. Rompendo barreiras: ensaios de literatura brasileira e hispanoamericana. Rio de Janeiro: 7 Letras, 2014.

RÓNAI, Paulo. As estórias de Tutaméia In: ROSA, João Guimarães. Tutameia terceiras estórias. Rio de Janeiro: José Olympio, 1976.

ROSA, João Guimarães. Tutameia terceiras estórias. Rio de Janeiro: José Olympio, 1976.

ROSA, João Guimarães. Ficção Completa. Vol. 1 e 2. Rio de Janeiro: Nova Aguilar, 1994.

SARAIVA, F. R. dos Santos. Dicionário LatinoPortuguês. Rio de Janeiro: Livraria Garnier, 2006

VIVEIROS DE CASTRO, Eduardo. A inconstância da alma selvagem e outros ensaios de antropologia. São Paulo: Cosac Naify, 2002.

VIVEIROS DE CASTRO, E. Metafísicas canibais: elementos para uma antropologia pós-estrutural. São Paulo: Cosac Naify, 2015.

\section{COMO CITAR ESSE ARTIGO}

VARNIERI, Marcos Lampert; SILVEIRA, Regina da Costa da. Animismo e tentação no conto Umas formas, de Guimarães Rosa. Signo, Santa Cruz do Sul, v. 42, n. 74, p. 96-104, maio 2017. ISSN 1982-2014. Disponível em: $<$ https://online.unisc.br/seer/index.php/signo/article/view/8854>. Acesso em: doi: http://dx.doi.org/10.17058/signo.v42i74.8854. 